\title{
Characterization and Synthesis of Some $\alpha, \beta$-unsaturated Ester Derivatives from Aliphatic Aldehydes
}

\author{
M. A. Bari, M. R. Karim, M. M. Hoque, and M. A. J. Miah ${ }^{1}$ \\ ${ }^{1}$ Department of Chemistry, Rajshahi University, Rajshahi-6205, Bangladesh
}

Received 21 January 2010, accepted in final revised form 22 March 2010

\begin{abstract}
Ethyl diazoacetate compound is useful synthetic intermediates for $\alpha, \beta$-unsaturated ester in organic synthesis but, due to its toxicity and unpredictable explosive behaviour, its unique reactivity has not been fully exploited and the use on large scale has been avoided. We have developed a reliable method that generates EDA compound in situ. Our approach is based on the Wittig reaction, which utilizes EDA as diazo precursors. In the presence of $\mathrm{Cu}(\mathrm{OTf})_{2}$, we found that diazo compounds can be cleanly converted to alkenyl compounds under mild reaction conditions and in a narrow range of solvents. These diazo compounds can then be induced to react directly with aldehydes to synthesize olefin. We have shown the usefulness of this chemistry in a number of different transformations, such as Wittig olefination reactions chemistry as applied toward the synthesis of more complicated molecules.
\end{abstract}

Keywords: $\alpha, \beta$-unsaturated ester; Acryclic acid ethyl ester; Aliphatic aldehyde; $\mathrm{Cu}(\mathrm{II})$ triflate; Triphenylphosphine.

(C) 2010 JSR Publications. ISSN: 2070-0237 (Print); 2070-0245 (Online). All rights reserved.

DOI: $10.3329 /$ jsr.v2i2.4167 J. Sci. Res. 2 (2), 343-350 (2010)

\section{Introduction}

Carbon-carbon bond formation is a common reaction in organic chemistry. Wittig reaction variants are widely used for the synthesis of $\alpha, \beta$-unsaturated esters from aldehydes is very common carbon-carbon bond forming reaction, especially catalytic asymmetric multicomponent reactions (CAMCRs), in which three or more reactants are combined in a single chemical step stereoselectively, have received considerable attention [1-3]. In most cases the problem with their unsatisfactory atom economy resulting in significant bye-product formation. Horner-Wadsworth-Emmons reaction is an alternative modified approach suggested by different research groups, such as Cynthia Burnell-Curty Research group have focused on the development of new synthetic methods using stannylenes and germylenes. With regard to stannylenes, they have found that acetals may

\footnotetext{
${ }^{1}$ Corresponding author: miahmaj@yahoo.com (Vice-Chancellor, Begum Rokeya University, Rangpur, Bangladesh)
} 
be selectively hydrolyzed to aldehydes under mildly basic conditions in the presence of tin(II) chloride [4 -9]. In addition, Knoevenagel reaction is the decarboxylative alternative methodology for the synthesis of $\alpha, \beta$-unsaturated esters from aldehydes using malonate half ester, but it is seldom used [10].

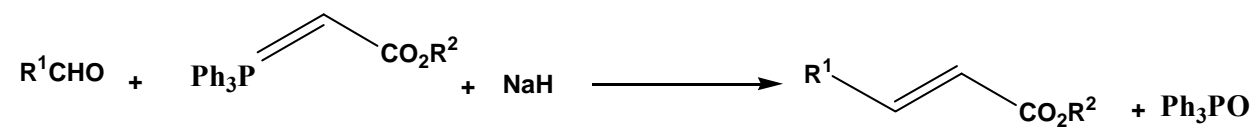

Scheme 1

Although, phosphorous based reagents are expensive but the corresponding half-esters of malonates can be obtained from inexpensive dialkylmalonate (scheme 1). Furthermore, by the reaction with enolizable aldehydes, $\alpha, \beta$-unsaturated esters (or their mixtures) are not commonly obtained, most importantly, in this method $(E)$ vs $(Z)$ selectivity varies [1113]. In this context Benjamin et al. [14-15 ] explored the synthesis of $\alpha, \beta$-unsaturated esters from malonate half esters with aldehyde and carried out the reaction in the presence of catalytic amount of 4-dimethylaminopyridine (DMAP, $10 \mathrm{~mol} \%$ ) at room temperature which provided the corresponding unsaturated esters with the remarkable result. To produce olefin the reaction of carbonyl compounds with diazo reagents, in most cases, diazoacetate derivatives, a number of transition metal complexes derived from Mo, $\mathrm{Re}, \mathrm{Fe}, \mathrm{Ru}, \mathrm{Co}$, and Ir are used significantly as catalyst [16 -26]. Recently a research group reported [27] the formation of esters from the reaction of carbonyl compounds with diazoacetate using lanthanide triflates as catalyst. Among the various metal triflates copper (II) triflate $\left[\mathrm{Cu}(\mathrm{OTf})_{2}\right]$, plays an indispensable role in the discovery of novel and improved reaction process. $\left[\mathrm{Cu}(\mathrm{OTf})_{2}\right]$, has long been known to promote elimination reactions, oxidative coupling reactions and reactions of diazocompounds [28]. In our previous study, we report the formation of $\alpha, \beta$-unsaturated esters from aldehydes by using copper triflates as catalyst in the reaction between ethyl diazoacetate (EDA) and carbonyl compounds especially various aromatic aldehydes [9]. In the present work, a series of aliphatic Acryclic acid ethyl ester derivatives were evaluated and compared against aromatic acryclic acid ethyl ester.

As a part of our ongoing studies to search for new carbon-carbon bond formation processes using diazo compounds, our future studies will focus on exploring the full scope of this reaction to other carbonyl compounds.

\section{Experiments, Results and Discussion}

Our early studies mainly focused on the allyl aldehydes to give $\alpha, \beta$-unsaturated esters in excellent yields. The common reaction of aliphatic aldehyde was used as a model system for optimization of the reaction conditions using cupper(II) triflate was first examined under standard methods $\left(0.30 \mathrm{~mol} \%\right.$ catalyst, refluxing in $\mathrm{CHCl}_{3}, 0.5$ equiv EDA for $\left.7 \mathrm{hr}\right)$ (scheme 2). A complete series of reaction was achieved with entry 1-8 under the same 
conditions. Product yields and measured enantio selectivities from these reactions are presented in Table 1. High product yields are obtained in each case, and especially $\mathbf{1}$ was the highest achieved.

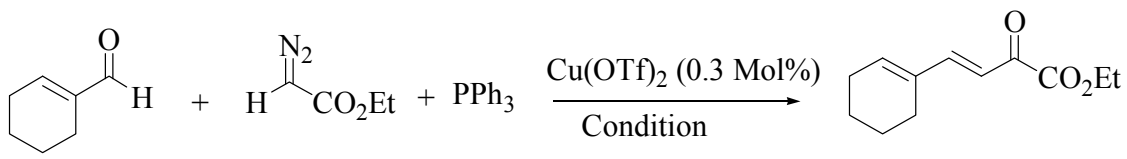

Scheme 2

Table 1 . Some aliphatic aldehydes (entry 1 to 8 ) have been treated in the same condition and gave corresponding $\alpha, \beta$-unsaturated ester.

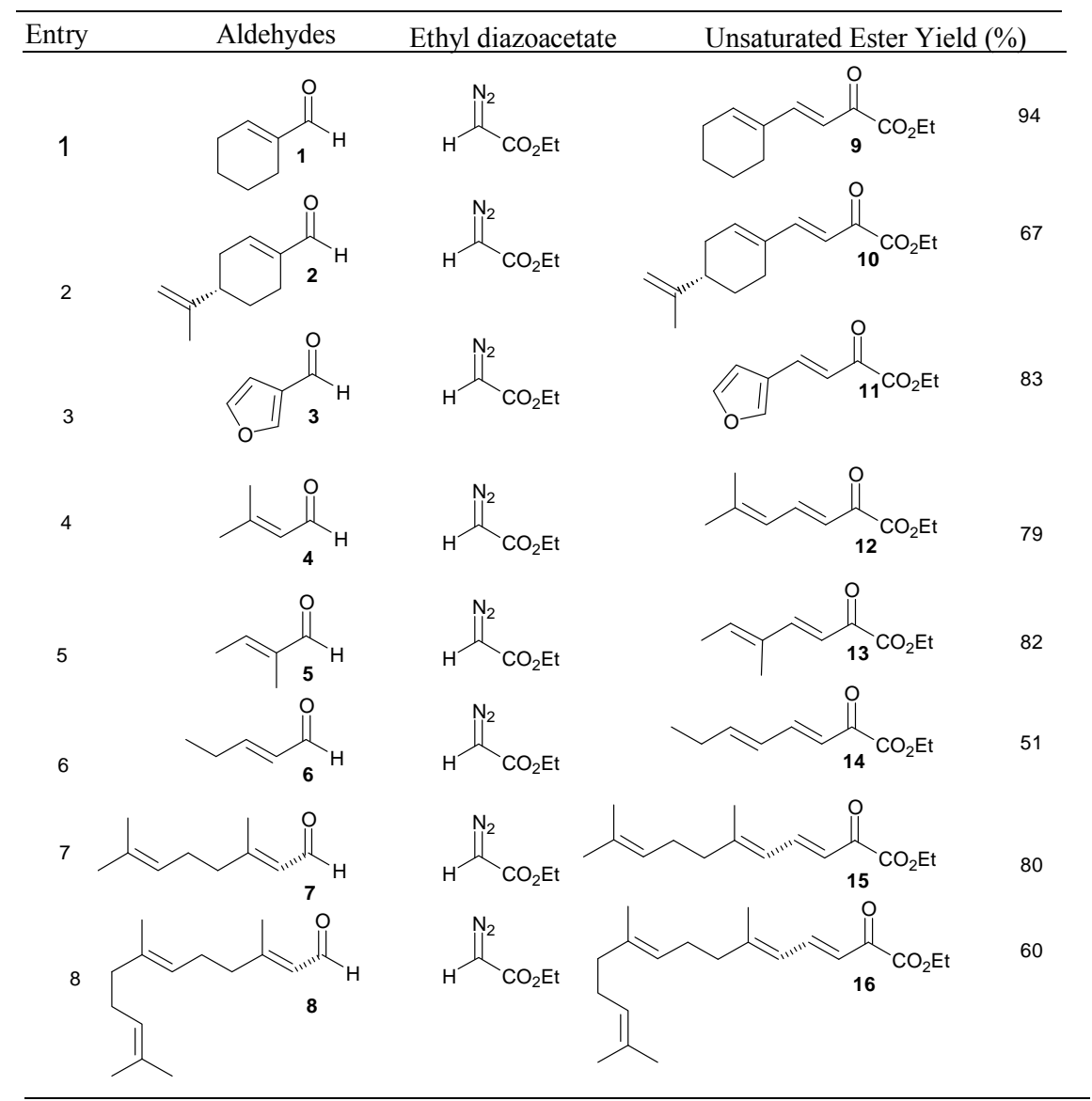

Catalyst: $\mathrm{Cu}(\mathrm{OTf})_{2}(0.3 \mathrm{Mol} \%)$

The reaction of aldehyde and ethylyl diazoacetate gave the corresponding conjugated ester derivatives 9-16 entry in above Table 1 . Initially a variety of reactions were tested in 
presence of copper (II) triflate conditions, employing different solvents such as chloroform, dichloromethane, tetrahydrofuran with different aldehyde at room temperature to elevated temperature. But the best results were obtained when the reaction was carried out in chloroform at $70^{\circ} \mathrm{C}$ (Table 2).

Table 2. Yields of products with different solvents using $\mathrm{Cu}(\mathrm{OTf})_{2}$.

\begin{tabular}{lll}
\hline Catalyst (eq) & Condition & Yield (\%) \\
\hline $\mathrm{Cu}(\mathrm{OTf})_{2}(0.3)$ & $\mathrm{CH}_{2} \mathrm{Cl}_{2}$, r.t & 0 \\
$\mathrm{Cu}(\mathrm{OTf})_{2}(0.3)$ & $\mathrm{CHCl}_{3}$, r.t & 0 \\
$\mathrm{Cu}(\mathrm{OTf})_{2}(0.3)$ & $\mathrm{PhF}$, r.t & 0 \\
$\mathrm{Cu}(\mathrm{OTf})_{2}(0.3)$ & $\mathrm{THF}$, r.t & 0 \\
$\mathrm{Cu}(\mathrm{OTf})_{2}(0.3)$ & $\mathrm{CHCl}_{3}, 70^{\circ} \mathrm{C}$ & 73 \\
\hline
\end{tabular}

We propose that the reason for the low reactivity of compound 6 (yield $51 \%$ ) at the electronically not favored aliphatic site of aldehyde is that the carbonyl group is very sterically unfair and unable to approach this site for reaction. In order to design systems capable of clean reactions at $\mathrm{C}=\mathrm{O}$ sites, the site would need to be electronically activated while the rest of the molecule must have no activated sites or the sites would need to be sterically protected. No alkyl group next to double bond occurred, presumably because the electrons are delocalized into the double bond and are not sufficiently activating the carbonyl group. One obvious system would be 1-cyclohexenyl-acetaldehyde (1) as the cyclohexene group would activate the site and sterically favor the carbonyl group. $\mathrm{Cu}(\mathrm{OTf})_{2}$ catalyzed the decomposition of ethyl diazoacetate at $70^{\circ} \mathrm{C}$ resulting in efficient $\mathrm{C}=\mathrm{O}$ activation generating 9 in $94 \%$ yield. In order to explore the scope of this reaction, the effect of temperature and the substituent on the aldehyde compound was examined and the results are summarized in Table 1 . In the case of compound 2 , which has parapropene substituted, an efficient reaction was obtained at $67 \%$ yield and the next compound 3 was improved (yield $83 \%$ ) on the adding aromatic ring. In the case of 5,9,13-Trimethyl-tetradeca-2,4,8,12-tetraenyl substitution of aldehyde (8) lowering the yields of 16 was obtained at $60 \%$ only, while in the case of rest of the compounds would generate steadily good yield.

This induction is in agreement with our published model [29] that predicts that the product would be formed. The absolute structure of the other products is assigned assuming a similar effect. Very efficient reactions were also obtained with the even more electron-rich aromatic system 11. Once again, reaction of ethyl diazoacetate with $\mathbf{8}$ at $70^{\circ} \mathrm{C}$ resulted in very less effective $\mathrm{C}=\mathrm{C}$ insertion to form product 16 in only $60 \%$ yield. The demonstration that EDA with a very electron-rich aromatic ring is an appropriate substrate how steric factor effects the aromatic ring from reaction with the carbonyl group. 
When the reaction was conducted with an excess of EDA (2 equiv.), the product was obtained in $83 \%$ yield.

In order to determine the $\mathrm{C}=\mathrm{O}$ activation into aldehyde site required the presence of a strong electrondonating group in the left position; the reaction was extended to high product. Moreover, treatment of EDA with formaldehyde in a $\mathrm{Cu}$ (II) catalyzed reaction afforded no product and also the reaction did not progress without $\mathrm{PPh}_{3}$. In case of the nonattendance or lack of catalyst, the reaction afforded azine as main product while the reaction mixture was stirred for 2 days.

The expected structures of the products have been established by the spectral data (IR, $\left.{ }^{1} \mathrm{H}-\mathrm{NMR}\right)$. The ${ }^{1} \mathrm{H}$ NMR spectra of the compounds 9-16 were not identical, but the characteristic spectra of two double bond hydrogen of those compounds were similar in all cases. Two geminal protons appeared nearly at $7.24 \sim 7.60 \mathrm{ppm}$ as doublets and the coupling constant was about $15.8 \mathrm{~Hz}$ and $6.12 \sim 6.14 \mathrm{ppm}$ was for nearest proton, while the other protons appeared in the aromatic and aliphatic regions, respectively.

\section{Experimental Section}

\section{General method}

$1 \mathrm{H}$ NMR spectra were run at $300 \mathrm{MHz}$ with the sample solvent being $\mathrm{CDCl}_{3}$ unless otherwise noted. IR spectra were obtained using a Nicolet Impact series 420 IR Spectrometer as $\mathrm{KBr}$ pellet or sodium chloride plate. Column chromatography was carried out on silica gel $60(230-400)$ meshes.

Thin layer chromatography (TLC) plate made by Merck (aluminum 5554) was used and visualized by UV lamp (254-365nm). The color can be determined by dipping into the solution of $300 \mathrm{ml} \mathrm{MeOH}, 9.0 \mathrm{~g}$ Vanillin and $1.5 \mathrm{ml} \mathrm{H}_{2} \mathrm{SO}_{4}(98 \%)$ and then burning by heat gun. All commercial reagents purchased from Aldrich Sigma (American) and Junsei (Japanese), were used without further purification.

\section{General Procedure}

A mixture of aldehyde $(1.0 \mathrm{mmol})$ and the appropriate ethyl diazo acetate $(2 \mathrm{mmol})$ was taken in a well-dried RB flask under nitrogen atmosphere. The reaction mixture was stirred in the presence of $\mathrm{Cu}(\mathrm{OTf})_{2}(0.3 \mathrm{mmol})$ and chloroform $(7 \mathrm{ml})$ at $70^{\circ} \mathrm{C}$ for $7-10 \mathrm{~h}$ duration to obtain a clear crude product. Then the crude product was purified by column chromatography (hexane-EtOAc) on silica gel to give corresponding $\alpha, \beta$-unsaturated ester(916).

\section{3-Cyclohex-1-enyl-acrylic acid ethyl ester (9)}

1H NMR (300 MHz, $\left.\mathrm{CDCl}_{3}\right): \delta=7.26(\mathrm{~d}, J=15.8 \mathrm{~Hz}, 1 \mathrm{H}), 6.14(\mathrm{t}, J=4.1 \mathrm{~Hz}, 1 \mathrm{H}), 5.35$ $(\mathrm{d}, J=15.8 \mathrm{~Hz}, 1 \mathrm{H}), 4.18(\mathrm{q}, J=7.1 \mathrm{~Hz}, 2 \mathrm{H}), 2.19-2.10(\mathrm{~m}, 4 \mathrm{H}), 1.71-1.55(\mathrm{~m}, 4 \mathrm{H}) 1.27$ (t, $J=7.1 \mathrm{~Hz}, 3 \mathrm{H})$.

IR (neat):2932, 1717, 1630, 1451, 1306, 1267, 1165, 1036, 982, $833 \mathrm{~cm}^{-1}$. 
3-(4-Isopropenyl-cyclohex-1-enyl)-acrylic acid ethyl ester (10)

1H NMR (300 MHz, CDCl3): $\delta=7.28(\mathrm{~d}, J=15.8 \mathrm{~Hz}, 1 \mathrm{H}), 6.16(\mathrm{q}, J=2.8 \mathrm{~Hz}, 1 \mathrm{H}), 5.75$ $(\mathrm{d}, J=15.8 \mathrm{~Hz}, 1 \mathrm{H}), 4.73-4.70(\mathrm{~m}, 2 \mathrm{H}), 4.18(\mathrm{q}, J=7.1 \mathrm{~Hz}, 2 \mathrm{H}), 2.35-2.10(\mathrm{~m}, 5 \mathrm{H}), 1.93-$ $1.87(\mathrm{~m}, 1 \mathrm{H}), 1.73(\mathrm{~s}, 3 \mathrm{H}), 1.52-1.46(\mathrm{~m}, 1 \mathrm{H}), 1.27(\mathrm{t}, J=7.1 \mathrm{~Hz}, 3 \mathrm{H})$.

IR (neat): 2980, 2928, 1715, 1632, 1449, 1368, 1304, 1165, 1040, 982, 889, $820 \mathrm{~cm}^{-1}$.

\section{3-Furan-3-yl-acrylic acid ethyl ester (11)}

1H NMR (300 MHz, CDCl3): $\delta=7.62$ (s, 1H), 7.55 (d, $J=15.8 \mathrm{~Hz}, 1 \mathrm{H}), 7.40(\mathrm{~s}, 1 \mathrm{H}), 6.56$ $(\mathrm{s}, 1 \mathrm{H}), 6.30(\mathrm{~d}, J=15.8 \mathrm{~Hz}, 1 \mathrm{H}), 4.22(\mathrm{q}, J=7.1 \mathrm{~Hz}, 2 \mathrm{H}), 1.30$ (t, $J=7.1 \mathrm{~Hz}, 3 \mathrm{H})$.

IR (neat): 2984, 2932, 1715,

$1645,1368,1314,1267,1221,1179,1155,1038,978,872,799 \mathrm{~cm}^{-1}$.

\section{5-Methyl-hexa-2, 4-dienoic acid ethyl ester (12)}

$1 \mathrm{H}$ NMR (300 MHz, CDCl3): $\delta=7.53(\mathrm{dd}, J=11.6,15.2 \mathrm{~Hz}, 1 \mathrm{H}), 5.96(\mathrm{~d}, J=11.6 \mathrm{~Hz}$, $1 \mathrm{H}), 5.74(\mathrm{~d}, J=15.2 \mathrm{~Hz}, 1 \mathrm{H}), 4.17(\mathrm{q}, J=7.1 \mathrm{~Hz}, 2 \mathrm{H}), 1.87(\mathrm{~s}, 3 \mathrm{H}), 1.85(\mathrm{~s}, 3 \mathrm{H}), 1.27$ (t, $J=7.1 \mathrm{~Hz}, 3 \mathrm{H})$.

IR (neat): 2980, 2932, 1713, 1640, 1447, 1368, 1306, 1277, 1213, 1140, 1040, 992,882 $\mathrm{cm}^{-1}$.

\section{4-Methyl-hexa-2,4-dienoic acid ethyl ester (13)}

1H NMR (300 MHz, CDCl3): $\delta=7.30$ (d, $J=15.7 \mathrm{~Hz}, 1 \mathrm{H}), 5.95$ (q, $J=7.0 \mathrm{~Hz}, 1 \mathrm{H}), 5.76$ $(\mathrm{d}, J=15.7 \mathrm{~Hz}, 1 \mathrm{H}), 4.18(\mathrm{q}, J=7.1 \mathrm{~Hz}, 2 \mathrm{H}), 1.79(\mathrm{~d}, J=7.0 \mathrm{~Hz}, 3 \mathrm{H}), 1.74(\mathrm{t}, J=1.0 \mathrm{~Hz}$, $3 \mathrm{H}), 1.28(\mathrm{t}, J=7.1 \mathrm{~Hz}, 3 \mathrm{H})$.

IR (neat): 2982, 2928, 1715, 1622, 1447, 1368, 1302, 1175, 1038, 982,820 cm-1.

\section{Hepta-2,4-dienoic acid ethyl ester (14)}

1H NMR (300 MHz, CDCl3): $\delta=7.24-7.16(\mathrm{~m}, 1 \mathrm{H}), 6.12-6.08(\mathrm{~m}, 2 \mathrm{H}), 5.72(\mathrm{~d}, J=$ $15.3 \mathrm{~Hz}, 1 \mathrm{H}), 4.14(\mathrm{q}, J=7.1 \mathrm{~Hz}, 2 \mathrm{H}), 2.18-2.08(\mathrm{~m}, 2 \mathrm{H}), 1.22(\mathrm{t}, J=7.1 \mathrm{~Hz}, 3 \mathrm{H}), 0.98(\mathrm{t}, J$ $=7.4 \mathrm{~Hz}, 3 \mathrm{H})$.

IR (neat): 2970, 1715, 1644, 1618, 1462, 1367, 1302, 1186, 1142, 1001, $876 \mathrm{~cm}^{-1}$.

\section{5,9-Dimethyl-deca-2,4,8-trienoic acid ethyl ester (15)}

1H NMR (300 MHz, CDCl3): $\delta=7.60-7.49(\mathrm{~m}, 1 \mathrm{H}), 5.96(\mathrm{~d}, J=11.6 \mathrm{~Hz}, 1 \mathrm{H}), 5.75$ (dd, $J$ $=7.8,15.2 \mathrm{~Hz}, 1 \mathrm{H}), 5.10-5.02(\mathrm{~m}, 1 \mathrm{H}), 4.18(\mathrm{~d}, J=7.1,1.2 \mathrm{~Hz}, 2 \mathrm{H}), 2.29(\mathrm{t}, J=7.2 \mathrm{~Hz}$, $1 \mathrm{H}), 2.12(\mathrm{~d}, J=3.1 \mathrm{~Hz}, 2 \mathrm{H})$,

2.02, (s, 1H), 1.87-1.85 (m, 3H), $1.66(\mathrm{~s}, 3 \mathrm{H}), 1.58(\mathrm{~s}, 3 \mathrm{H}), 1.27(\mathrm{t}, J=7.1 \mathrm{~Hz}, 3 \mathrm{H})$.

IR (neat): 2926, 2857, 1715, 1636, 1649, 1368, 1275, 1152, 1038, 980, $887 \mathrm{~cm}^{-1}$.

\section{5, 9,13-Trimethyl-tetradeca-2,4,8,12-tetraenoic acid ethyl ester (16)}

1H NMR (300 MHz, CDCl3): $\delta=7.60-7.48(\mathrm{~m}, 1 \mathrm{H}), 5.96(\mathrm{~d}, J=11.6 \mathrm{~Hz}, 1 \mathrm{H}), 5.74(\mathrm{dd}, J$ $=6.5,15.2 \mathrm{~Hz}, 1 \mathrm{H}), 5.09-5.04(\mathrm{~m}, 2 \mathrm{H}), 4.21-4.12(\mathrm{~m}, 2 \mathrm{H}), 2.32-2.23(\mathrm{~m}, 1 \mathrm{H}), 2.17-2.12$ $(\mathrm{m}, 3 \mathrm{H}), 2.01-1.95(\mathrm{~m}, 4 \mathrm{H})$ 
$1.87-1.85(\mathrm{~m}, 3 \mathrm{H}), 1.66(\mathrm{~s}, 3 \mathrm{H}), 1.58(\mathrm{~s}, 6 \mathrm{H}), 1.27(\mathrm{t}, J=7.1 \mathrm{~Hz}, 3 \mathrm{H})$.

IR (neat): 2967, 2926, 1715, 1447, 1368, 1275, 1148, 1030, 980, 887, $822 \mathrm{~cm}^{-1}$.

\section{Conclusions}

We have demonstrated that effective $\mathrm{C}=\mathrm{O}$ activation of aldehyde groups can be achieved as long as the olefin is least substituted. The aromatic ring and aliphatic group substituted compounds are more reactive than that of olefin compounds. Furthermore, the reaction between EDA and carbonyl compounds are catalyzed well by copper triflate catalysts and proves to be a fairly good catalyst. In addition, a salient feature of copper (II) triflate is its inherent stability in aqueous solvents that open the door to environmental chemistry [30]. In addition, the electrophilic attack is accomplished by the copper (II) carbonyl intermediates. Thus, the $\mathrm{C}=\mathrm{O}$ activation strategy we have presented herein offers exciting new options for the synthesis of $\alpha, \beta$-unsaturated compounds as illustrated in the very concise route to acryclic acid ethyl ester.

\section{References}

1. H. C. Guo and J. A. Ma, Angew. Chem. Int. Ed. 45, 354 (2006). doi:10.1002/anie.200500195

2. B. E. Maryanoff and A. B. Reitz, Chem. Rev. 89, 863 (1989). doi:10.1021/cr00094a007

3. Daniel Romo, D. D. Johnson, L. Plamondon, T. Miwa, and S. L. Schreiber, J. Org. Chem. 57 (19), 5061 (1992).

4. C. Burnell-Curty and E. J. Roskamp, J. Org. Chem. 57, 5063 (1992). doi:10.1021/jo00045a009

5. K. L. Ford and E.J.Roskamp, Tetrahedron Lett. 33, 1135 (1992). doi:10.1016/S0040-4039(00)91878-1

6. M. Hatsuda, T. Kuroda, M. Seki, Synth. Commun. 33, 427 (2003). doi:10.1081/SCC-120015773

7. C. R. Holmquist and E. J. Roskamp, J. Org. Chem. 54, 3258 (1989). doi:10.1021/jo00275a006

8. C. R. Holmquist and E. J. Roskamp, Tetrahedron Lett. 31, 4991 (1990). doi:10.1016/S0040-4039(00)97786-4

9. C. R. Holmquist and E. J. Roskamp, Tetrahedron Lett. 33, 1331 (1992). doi:10.1016/S0040-4039(00)91877-X

10. E. Knoevenagel, J. Am .Chem. Soc. 68, 376 (1945).

11. T. Carmona, J. Fuentes, I. Robina, E. Rodriguez Garcia, R. Demange, P. Vogel and A.L. Winters, J. Org. Chem. 68, 3874 (2003). doi:10.1021/jo026688a

12. W. F.Shi, M..Ma and J. B.Wang, Chinese Chemical Letters 15 (8), 911 (2004).

13. Personal communication with Dr. Lingaiah Nagarapu, Indian Institute of Chemical Tech., India (2010).

14. N. Bremeyer, S. C. Smith, S. V. Ley, and M. J. Gaunt, Angew. Chem. Int. Ed. 43, 2681 (2004). doi:10.1002/anie. 200454007

15. L. Benjamin, D. Arno, T. Maria, F. Hechavarria, W. Kathrin, v. t. Hendrik, R. T. Ramon, L. G. Pedro, Commun, 347, 1558 (2005).

16. X. Lu, H. Fang, and Z. Ni, J. Organomet. Chem. 373, 77 (1989). doi:10.1016/0022-328X(89)85027-2

17. W. A. Herrmann and M. Wang, Angew. Chem. Int. Ed. Engl. 30, 1641 (1991). doi:10.1002/anie.199116411

18. W. A. Herrmann, P. W. Roesky, M. Wang, and W. Scherer, Organometallics 13, 4531 (1994). doi:10.1021/om00023a064

19. G. A. Mirafzal, G. L. Cheng, and L. K. Woo, J. Am. Chem. Soc. 124, 176 (2002). 
doi:10.1021/ja016721v

20. G. L. Cheng, G. A. Mirafzal, and L. K.Woo, Organometallics 22, 1468 (2003). doi:10.1021/om020904o

21. Y. Chen, L. Huang, M. A. Ranade, and X. P. Zhang, J. Org. Chem. 68, 3714 (2003). doi: $10.1021 /$ jo0341158

22. O. Fujimura and T. Honma, Tetrahedron Lett. 39, 625 (1998). doi:10.1016/S0040-4039(97)10661-X

23. F. E. Kuhn, A. M. Santos, A. A. Jpgalekar, F. M. Pedro, P. Rigo, and W. Baratta, J. Catal. 227, 253 (2004). doi:10.1016/j.jcat.2004.07.011

24. M. Y. Lee, Y. Chen, and X. P. Zhang, Organometallics 22, 4905 (2003). doi:10.1021/om034115y

25. E. Erturk and A. S. Demir, Tetrahedron 64, 7555 (2008). doi:10.1016/j.tet.2008.05.108

26. H. Lebel and C. Ladjel, Organometallics 27, 2676 (2008). doi:10.1021/om800255c

27. M. Curini, F. Epifano, M. C. Marcotullio, and O. Rosati, Eur. J. Org. Chem, 2002, 1562 (2002). doi:10.1002/1099-0690(200205)2002:9<1562::AID-EJOC1562>3.0.CO;2-Q

28. K. K. Laali: in Encyclopedia of Reagents for Organic synthesis, vol. 2, ed. L.A. Paquette (Wiley, New York, 1995) p. 1380, and references cited therein.

29. M. A. Bari, M. I. Hossain, and M. A. J. Miah, J. Sci. Res. 1 (3), 635 (2009). DOI: $10.3329 /$ jsr.v1i3.2473

30. C. Hertweck, Journal für praktische Chemie 342 (3), 316 (2000). doi:10.1002/(SICI)1521-3897(200003)342:3<316::AID-PRAC316>3.0.CO;2-S 